\title{
Investigation of Power Flow Effect of Serial and Parallel FACTS Devices
}

\author{
H.Bakir, A.Ozturk, and S.Tosun
}

\begin{abstract}
It is difficult to increase the capacity of the transmission system by establishing new lines or switching to a new voltage level to meet the rapidly rising electricity demand. Thus, there is an increased need for power flow controllers that can increase the capacity of the existing transmission line and control power flows in predetermined transmission corridors. For this reason, in recent years a new class of controllers has emerged called Flexible AC Transmission System (FACTS). It is very important to investigate the advantages of FACTS devices and to model these devices so that power systems can be operated in steady state. In this study, a comprehensive modeling of the most popular FACTS devices for power flow operation was performed. Power flow studies were first performed using the Newton Raphson method for an IEEE 5-bus power system without any FACTS devices. Then, different FACTS controllers were added to the system to perform power flow studies. As a result of the power flow studies performed, it was observed that the FACTS controllers increased the capacity of the existing transmission line and contributed to the voltage stability.
\end{abstract}

Index Terms - FACTS devices, newton-raphson, power flow, voltage stability.

\section{INTRODUCTION}

$\mathrm{T}$ HE ENERGY industry is undergoing a profound transformation around the world. Decreases in natural resources and increasing demand for electricity are some of the reasons for this change. Many studies have been done to maximize the capacity of existing transmission systems with high reliability and stability. The work carried out has pointed to the need for a power electronic based controller because of the slow response times of the controllers based on electromechanical technology and high maintenance costs [1]. Until recently, active and reactive power control in Alternating Current (AC) transmission networks was done by carefully adjusting the transmission line impedances to adjusting the

H. BAKIR, is with Department of Electrical and Electronics Engineering University of Düzce University, Düzce, Turkey, (e-mail: hsynbakr@gmail.com)

A. OZTURK, is with Department of Electrical and Electronics Engineering University of Düzce University, Düzce, Turkey, (e-mail: aliozturk@duzce.edu.tr).

S. TOSUN, is with Department of Electrical and Electronics Engineering University of Düzce University, Düzce, Turkey, (e-mail: salihtosun@duzce.edu.tr).

Manuscript received September 13, 2017; accepted January 08, 2018 DOI: $10.17694 /$ bajece.410204 generator excitation control and transformer step changes and terminal voltage.

FACTS technology has a critical role in transmission line planning. Because it creates new opportunities to control the power and increase the available capacity [2, 3].

Due to the increase in population and economy, there is a need to increase the flexibility, reliability and capacity of existing transmission systems. Due to changing market conditions, electrical utilities are looking for various ways to operate existing transmission lines at maximum limits. To achieve these goals, FACTS devices are used that can control the power flow and increase the transmission capacity [4]. FACTS devices commonly used in power systems are Static Var Compensator (SVC), Static Synchronous Compensator (STATCOM), Thyristor Controlled Series Compensator (TCSC), Static Synchronous Series Compensator (SSSC) and Unified Power Flow Controller (UPFC) [6].

\section{POWER FLOW ANALYSIS}

It is necessary to plan the operation of the power systems under the existing conditions and to carry out the load flow for the future situation. With load flow studies, voltage magnitudes and angles at each bar of the steady-state system can be obtained. Active and reactive power capacities are obtained in each line when the bus voltages and angles are calculated. Also losses in the lines can be calculated depending on the difference in the sender and receiver ends. The most preferred power flow method is the NewtonRaphson method because of its reliability in terms of convergence $[7,8]$.

\section{A. Newton-Raphson Method}

The Newton-Raphson method is one of the most common power flow solution methods that operate iteratively. This method is a classic method based on the Taylor series expansion and approaching well in a short time [5].

In Eq. (1) bus variables; $n$ total number of bara $i$ and $j$ bara numbers [2].

$I_{i}=\sum_{j=1}^{n} Y_{i j} V_{j}$

In large scale power flow studies, the Newton Raphson power flow is the most successful because of its strong convergence 
feature. The Newton-Raphson power flow algorithm is expressed by Eq. (2) $[10,11]$.

$\left[\begin{array}{l}\Delta P \\ \Delta Q\end{array}\right]-\left[\begin{array}{ll}\Delta P / \Delta \theta & \Delta P /(\Delta V / V) \\ \Delta Q / \Delta \theta & \Delta Q /(\Delta V / V)\end{array}\right]\left[\begin{array}{c}\Delta \theta \\ (\Delta V / V)\end{array}\right]$

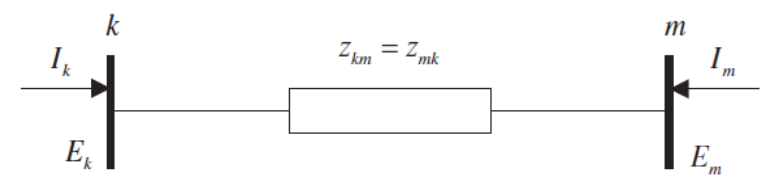

Fig. 1. Equivalent impedance

For the system in Fig. 1, the Jacobian matrix elements are constructed according to the following equations [8].

For $\mathrm{k} \neq \mathrm{m}$;

$\frac{\partial P_{k, 1}}{\partial Q_{m, 1}}=V_{k} V_{m}\left[G_{k m} \sin \left(\theta_{k}-\theta_{m}\right)-B_{k m} \cos \left(\theta_{k}-\theta_{m}\right)\right]$

$\frac{\partial P_{k, 1}}{\frac{\partial V_{m, 1}}{V_{m, 1}}}=V_{k} V_{m}\left[G_{k m} \cos \left(\theta_{k}-\theta_{m}\right)+B_{k m} \sin \left(\theta_{m}-\theta_{m}\right)\right]$

$\frac{\partial Q_{k, 1}}{\partial \theta_{m, 1}}=-\frac{\partial P_{k, 1}}{\frac{\partial V_{m, 1}}{V_{m, 1}}}$

$\frac{\partial Q_{k, 1}}{\frac{\partial V_{m, 1}}{V_{m, 1}}}=\frac{\partial P_{k, 1}}{\partial \theta_{m, 1}}$

For $\mathrm{k}=\mathrm{m}$;

$\frac{\partial P_{k, 1}}{\partial \theta_{k, 1}}=-Q_{k}^{c a l}-V_{k}^{2} B_{k k}$

$\frac{\partial Q_{k, 1}}{\frac{\partial V_{k, 1}}{V_{k, 1}}}=P_{k}^{c a l}+V_{k}^{2} G_{k k}$

$\frac{\partial P_{k, 1}}{\partial \theta_{k, 1}}=-Q_{k}^{c a l}-V_{k}^{2} B_{k k}$

$\frac{\partial Q_{k, 1}}{\frac{\partial V_{m, 1}}{V_{m, 1}}}=Q_{k}^{c a l}-V_{k}^{2} B_{k k}$

\section{B. Test System Data}

The IEEE-5 bus power system constructed using the Power System Analysis Toolbox (PSAT) program was shown in Fig 2. The base values of the system were set at 100 MVA and $100 \mathrm{KV}$.

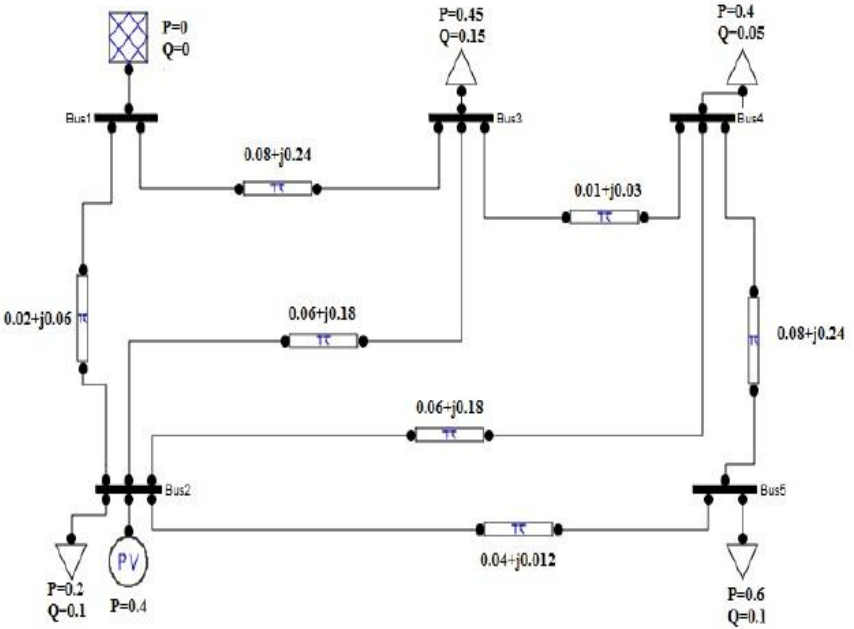

Fig. 2. IEEE-5 bus power system generated by PSAT

The generator and load data of the power system were shown in Table 1. The voltage and angle values obtained from the power flow for the IEEE 5-bus power system without FACTS were shown in Table 2.

TABLE I

GENERATOR AND LOAD DATA

\begin{tabular}{|c|c|c|c|c|}
\hline Bus Type & Bus No & $\begin{array}{c}\text { Voltage } \\
\text { (p.u) }\end{array}$ & $\begin{array}{c}\text { Active } \\
\text { Power (p.u) }\end{array}$ & $\begin{array}{c}\text { Reactive } \\
\text { Power (p.u) }\end{array}$ \\
\hline Slack & 1 & 1.06 & - & - \\
\hline P-V & 2 & 1.00 & 0.4 & - \\
\hline P-Q & 3 & - & 0.45 & 0.15 \\
\hline P-Q & 4 & - & 0.4 & 0.05 \\
\hline P-Q & 5 & - & 0.6 & 0.1 \\
\hline
\end{tabular}

TABLE II

VOLTAGE AND ANGLE VALUES WITHOUT FACTS

\begin{tabular}{|c|c|c|c|c|c|}
\hline Parameters & Bus 1 & Bus 2 & Bus 3 & Bus 4 & Bus 5 \\
\hline VM (p.u.) & 1.06 & 1 & 0.987 & 0.984 & 0.972 \\
\hline VA (degree) & 0.00 & -2.06 & -4.640 & -4.96 & -5.770 \\
\hline
\end{tabular}

\section{POWER FLOW MODEL OF FACTS DEVİCES}

\section{A. Static Var Compensator (SVC) Power Flow Model}

Two alternative power flow models are commonly used to assess the effect of the SVC controller on power system applications. These are the variable shunt susceptance model and the trigger angle model.

Variable shunt susceptance SVC model was shown in Fig. 3. The equivalent circuit shown in Fig. 3 is used to derive nonlinear power equations. In the equivalent circuit shown in Fig. 3, the SVC current equation was shown in Eq. (11). The reactive power equation of the SVC was shown in Eq. (12) [12].

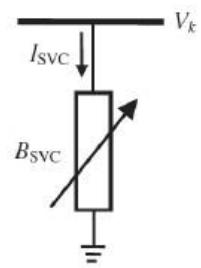

Fig. 3. Variable shunt susceptance SVC model 
$I_{S V C}=j B_{S V C} V_{k}$

$Q_{S V C}=-V_{k}^{2} B_{S V C}$

At the end of each iteration, the variable shunt susceptance is updated according to Eq. (13) [8].

$B_{S V C}{ }^{i}=B_{S V C}{ }^{(i-1)}+\left\{\frac{\Delta B_{S V C}}{B_{S V C}}\right\} B_{S V C}{ }^{(i-1)}$

Another SVC model is the trigger angle model. An alternative SVC model, which circumvents the additional iterative process, consists in handling the thyristor controlled reactor trigger angle $\alpha$ as a state variable in the power flow formulation. The SVC susceptance is obtained by Eq. (14) [8].

$Q_{k}=\frac{-V_{k}^{2}}{X_{C} X_{L}}\left\{X_{L}-\frac{X_{C}}{\pi}\left[2\left(\pi-\alpha_{S V C}\right)+\sin \left(2 \alpha_{S V C}\right)\right]\right\}$

Using the above equation, the linearized SVC equation is expressed by Eq. (15) [12].

$\left[\begin{array}{l}\Delta P_{k} \\ \Delta Q_{k}\end{array}\right](i)$
$=\left[\begin{array}{ll}0 \\ 0 & \frac{2 V_{k}^{2}}{\pi X_{L}}\left[\cos \left(2 \alpha_{S V C}\right)-1\right]\end{array}\right](i)\left[\begin{array}{c}\Delta Q_{k} \\ \Delta \alpha_{S V C}\end{array}\right](i)$

The trigger angle is updated according to equation (16) at the end of each iteration [12].

$\alpha_{S V C}{ }^{(i)}=\alpha_{S V C}{ }^{(i-1)}+\Delta \alpha_{S V C}{ }^{(i)}$

\section{B. Thyristor Controlled Series Compensator (TCSC) Power Flow Model}

Two alternative power flow models have been introduced to assess the effect of the TCSC controller in power system applications. The simple TCSC model uses the concept of variable series reactance. In this model, the series reactance is automatically adjusted to provide active power flow within the specified limits. The advanced model uses a nonlinear reactance trigger angle graph. In this model, the TCSC trigger angle is selected as the state variable in the Newton Raphson power flow solution [13].

The TCSC power flow model presented in this section is based on the simple concept of variable series reactance. The value is automatically set to limit the power flow to a certain value. The amount of reactance is determined effectively using Newton's method. Thyristor controlled series compensator equivalent circuit was shown in Fig. 4 [8].

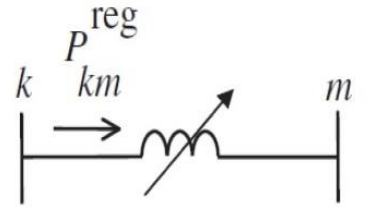

(a)



(b)
Fig. 4. Thyristor controlled series compensator equivalent circuit (a) inductive and (b) capacitive regions
The transfer matrix of the variable series compensator was shown in Eq. (17) [14].

$\left[\begin{array}{c}I_{k} \\ I_{m}\end{array}\right]=\left[\begin{array}{ll}j B_{k k} & j B_{k m} \\ j B_{m k} & j B_{m m}\end{array}\right]\left[\begin{array}{l}V_{k} \\ V_{m}\end{array}\right]$

The equations for inductive operation were shown in Eq. (18) and (19). For capacitive operation, the signals are inverted [14].

$B_{k k}=B_{m m}=-\frac{1}{X_{T C S C}}$
$B_{k m}=B_{m k}=\frac{1}{X_{T C S C}}$

The active and reactive power equations were shown in equations (20) and (21) [8].

$P_{k}=V_{k} V_{m} B_{k m} \sin \left(\theta_{k}-\theta_{m}\right)$

$Q_{k}=-V_{k}^{2} B_{k k}-V_{k} V_{m} B_{k m} \cos \left(\theta_{k}-\theta_{m}\right)$

The state variable $X_{T C S C}$ is updated at the end of each iterative step as in Eq. (22) [8].

$X_{T C S C}{ }^{(i)}=X_{T C S C}{ }^{(i-1)}+\left\{\Delta X_{T C S C} / X_{T C S C}\right\}(i) X_{T C S C}{ }^{(i-1)}$

The trigger angle model presented in this section uses the concept of equivalent series reactance to represent TCSC. After the reactance value is determined using the Newton method, the angle can be calculated. However, this calculation requires an iterative solution since the TCSC reactance value and the trigger angle $\alpha_{\text {TCSC }}$ are nonlinearly related [15].

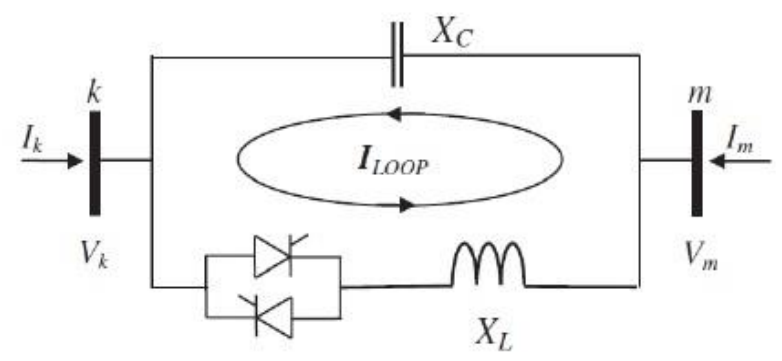

Fig. 5. TCSC Equivalent Circuit

The equivalent reactance of TCSC shown in Fig. 5 is calculated according to Eq. (23) [8].

$$
\begin{aligned}
& X_{T C S C}=-X_{C}+C_{1}\{2(\pi-\alpha)+\sin [2(\pi-\alpha)]\} \\
& -C_{2} \cos ^{2}(\pi-\alpha)\{\omega \tan [\omega(\pi-\alpha)]-\tan (\pi-\alpha)\} \\
& C_{1}=\frac{X_{C}+X_{L C}}{\pi} \\
& C_{2}=\frac{4 X_{L C}^{2}}{X_{L} \pi} \\
& X_{L C}=\frac{X_{C} X_{L}}{X_{C}-X_{L}}
\end{aligned}
$$


The active and reactive power equations of TCSC are as follows [14].

$P_{k}=V_{k} V_{m} B_{k m} \sin \left(\theta_{k}-\theta_{m}\right)$

$Q_{k}=-V_{k}^{2} B_{k k}-V_{k} V_{m} B_{k m} \cos \left(\theta_{k}-\theta_{m}\right)$

$B_{k k}=-B_{k m}=B_{T C S C}$

\section{Static Synchronous Compensator (STATCOM) Power Flow Model}

The static synchronous compensator (STATCOM) is represented by a synchronous voltage source with minimum and maximum voltage magnitude limits. The synchronous voltage source represents the fundamental fourier series component of the switched voltage waveform at the $\mathrm{AC}$ converter terminal of STATCOM [9]. The STATCOM equivalent circuit shown in Figure 6 is used to obtain the mathematical model of the controller to be included in power flow algorithms [16].

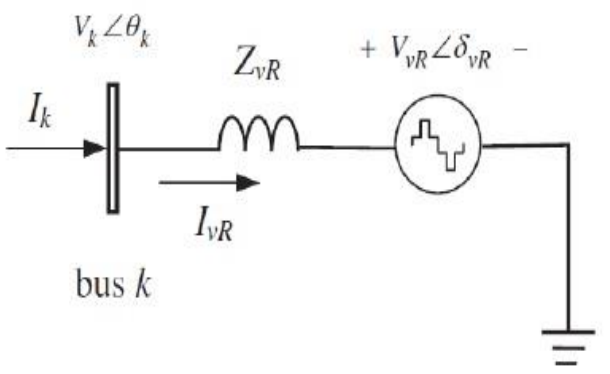

Fig. 6. STATCOM Equivalent Circuit

Based on the shunt connection shown in Figure 6, power flow equations for STATCOM can be written following.

$E_{v R}=V_{v R}\left(\cos \delta_{v R}+j \sin \delta_{v R}\right)$

$S_{v R}=V_{v R} I_{v R}{ }^{*}=V_{v R} Y_{v R}{ }^{*}\left(V_{v R}{ }^{*}-V_{k}{ }^{*}\right)$

The active and reactive power equations for the converter and $\mathrm{k}$ bus are obtained as follows.

$$
\begin{gathered}
P_{v R}=V_{v R}^{2} G_{v R}+V_{v R} V_{k}\left[G_{v R} \cos \left(\delta_{v R}-\theta_{k}\right)\right. \\
\left.+B_{v R} \sin \left(\delta_{v R}-\theta_{k}\right)\right] \\
Q_{v R}=-V_{v R}^{2} B_{v R}+V_{v R} V_{k}\left[G_{v R}-B_{v R} \cos \left(\delta_{v R}-\theta_{k}\right)\right] \\
P_{k}=V_{k}^{2} G_{v R}+V_{k} V_{v R}\left[G_{v R} \cos \left(\theta_{k}-\delta_{v R}\right)\right. \\
\left.+B_{v R} \sin \left(\theta_{k}-\delta_{v R}\right)\right] \\
\begin{aligned}
Q_{k}=-V_{k}^{2} B_{v R}+ & V_{k} V_{v R}\left[G_{v R} \sin \left(\theta_{k}-\delta_{v R}\right)\right. \\
- & \left.B_{v R} \cos \left(\theta_{k}-\delta_{v R}\right)\right]
\end{aligned}
\end{gathered}
$$

\section{SIMULATION RESULTS}

\section{A. Power Flow With SVC}

SVC was added to the IEEE-5 bus power system to examine the voltage control capability of the SVC controller. The power system with SVC controller was shown in Fig. 7. Before running the simulation, the amplitude value of the slack bus was set to 1.06 p.u and the amplitude of the PV bus was set to 1 p.u. SVC was placed in the Bus-3 to hold the bus voltage at 1 p.u. The inductive reactance value of the SVC was 0.288 p.u, and the capacitive reactance value was 1.07 p.u. The SVC trigger angle was initially set to 140 degrees. This value allows the SVC to operate in the capacitive region. The voltage magnitude and phase angle values obtained as a result of the power flow was shown in Table 3.

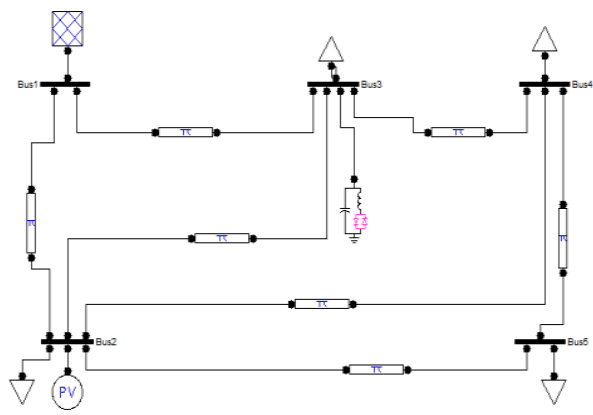

Fig. 7. IEEE-5 bus power system with SVC

TABLE III

VOLTAGE AND ANGLE VALUES OBTAINED FROM LOAD FLOW OF SYSTEM INCLUDING SVC

\begin{tabular}{|c|c|c|c|c|c|}
\hline Parameters & Bus 1 & Bus 2 & Bus 3 & Bus 4 & Bus 5 \\
\hline VM (p.u.) & 1.06 & 1 & 1 & 0.994 & 0.9752 \\
\hline VA (degree) & 0.00 & -2.053 & -4.837 & -5.107 & -5.797 \\
\hline
\end{tabular}

\section{B. Power Flow With TCSC}

As shown in Fig. 8, the IEEE-5 bus power system was modified to include the TCSC to compensate the transmission line between Bus 3 and Bus 4. The TCSC was added to the transmission line to control the active power flowing from Bus 3 to Bus 4 . The initial value of the TCSC was set to be equal to $\% 50$ of the inductive reactance value of the transmission line. The TCSC initial capacitive reactance value was 0.015 p.u and the triggering angle was 145 degrees.

As a result of the power flow, it was observed that the TCSC sets the active power value of the transmission line 3-4 to $21 \mathrm{MW}$. The voltage magnitude and phase angle values obtained from the power flow result for the system in Fig. 8 were shown in Table 4.

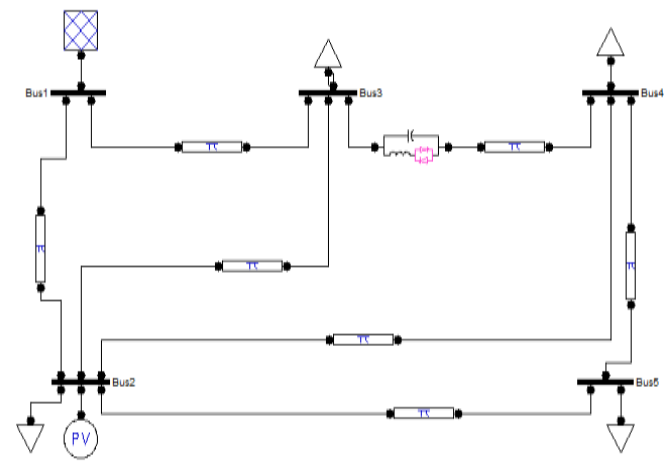

Fig. 8. IEEE-5 bus power system with TCSC 
TABLE IV

VOLTAGE AND ANGLE VALUES OBTAINED FROM LOAD FLOW OF SYSTEM INCLUDING TCSC

\begin{tabular}{|c|c|c|c|c|c|}
\hline Parameters & Bus 1 & Bus 2 & Bus 3 & Bus 4 & Bus 5 \\
\hline VM (p.u.) & 1.06 & 1 & 0.987 & 0.988 & 0.984 \\
\hline VA (degree) & 0 & -2.04 & -4.72 & -4.46 & -4.81 \\
\hline
\end{tabular}

\section{Power Flow With STATCOM}

STATCOM was added to Bus 3 of the IEEE- 5 bus power system in order to maintain the node voltage at 1 p.u. The initial source voltage of STATCOM was 1 p.u, the phase angle was 0 degree and the transformer reactivity was 10 p.u.

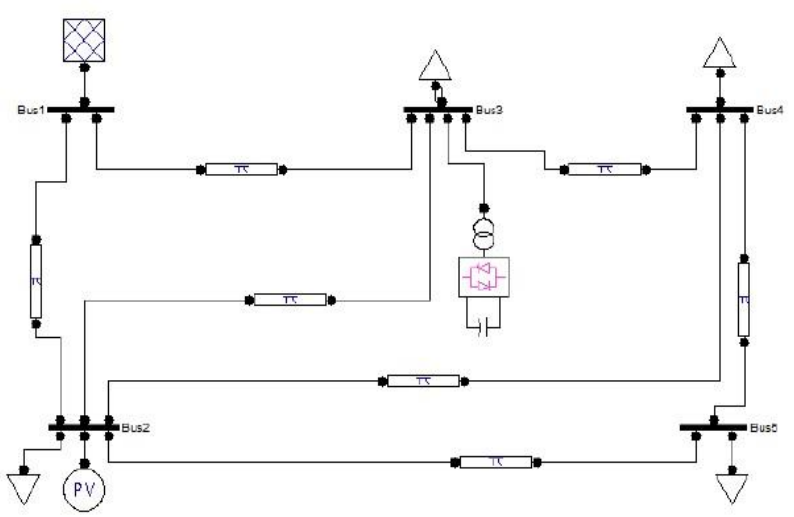

Fig. 9. IEEE-5 bus power system with STATCOM

It was observed from the power flow results that STATCOM produced 20.5 MVAR of power to hold the voltage at $1 \mathrm{p}$.u in Bus 3. The results in Table 5 showed that the use of STATCOM could improve the voltage profile.

TABLE V

VOLTAGE AND ANGLE VALUES OBTAINED FROM LOAD FLOW OF SYSTEM INCLUDING STATCOM

\begin{tabular}{|c|c|c|c|c|c|}
\hline Parameters & Bus 1 & Bus 2 & Bus 3 & Bus 4 & Bus 5 \\
\hline VM (p.u.) & 1.06 & 1 & 1 & 0.994 & 0.974 \\
\hline VA (degree) & 0 & -2.05 & -4.82 & -5.11 & -5.81 \\
\hline
\end{tabular}

\section{CONCLUSION}

In this study, the power flow of the IEEE-5 bus power system using the Newton-Raphson method was performed for situations with and without FACTS devices. Serial and parallel FACTS devices were added to the power system and serial and parallel compensation was performed. STATCOM and SVC from the parallel FACTS controllers were added to the system. In addition, TCSC is added to the system from serial FACTS controllers.

From the simulation results it is observed that parallel FACTS devices have an important role in voltage control and serial FACTS devices have an important role in increasing transmission line capacity. In series compensation, the line impedance is changed, which means that the net impedance is reduced and thus the transmittable active power is increased. In shunt compensation, it has been observed that even reactive current is injected to adjust the voltage at the connection point.

\section{REFERENCES}

[1] N.G. Hingorani, L. Gyugyi, and M. El-Hawary, Understanding FACTS: Concepts And Technology of Flexible AC Transmission Systems, IEEE press, 2000.

[2] N.G. Hingorani, "Flexible AC Transmission." IEEE Spectrum, Vol.30, No. 4, 1993, pp.40-45.

[3] R.M. Mathur, R.K. Varma, Thyristor-based FACTS Controllers For Electrical Transmission Systems, John Wiley \& Sons, 2002.

[4] X.P. Zhang, C. Rehtanz and B. Pal. "Congestion Management and Loss Optimization with FACTS. flexible ac transmission systems: modelling and control", 2006, pp.239-258

[5] V. Yamaçlı, K. Abacı, "Güç sistemlerinde aktif güç kaybının optimizasyonu", Elektrik - Elektronik - Bilgisayar ve Biyomedikal Mühendisliği Sempozyumu, Kasım 2014.

[6] B. Gao, G.K. Morison and P. Kundur, "Towards the development of a systematic approach for voltage stability assessment of large-scale power systems", IEEE transactions on power systems, Vol.11, No.3, 1996, pp.1314-1324.

[7] C.R. Fuerte-Esquivel and E. Acha, "A Newton-type algorithm for the control of power flow in electrical power networks", IEEE Transactions on Power Systems, Vol.12,No.4, 1997, pp.1474-1480

[8] E. Acha, C.R. Fuerte-Esquivel, H. Ambriz-Perez and C. AngelesCamacho, FACTS: Modelling and Simulation in Power Networks, John Wiley \& Sons, 2004.

[9] Y.H. Song, A. Johns, Flexible AC Transmission Systems (FACTS), IET,1999.

[10] F.Milano, "Continuous Newton's method for power flow analysis", IEEE Transactions on Power Systems, Vol.24, No.1, 2009, pp.50-57.

[11] R, Bonert, "A laboratory for power systems control with static converters", IEEE transactions on power systems, Vol.13, No.1, 1998, pp. $15-20$.

[12] H. Ambriz-Perez, E. Acha C. R. Fuerte-Esquivel, "Advanced SVC models for Newton-Raphson load flow and Newton optimal power flow studies", IEEE transactions on power systems, Vol.15, No.1, 2000, pp.129-136.

[13] Fuerte-Esquivel, C. R. and Acha, E. "Newton-Raphson algorithm for the reliable solution of large power networks with embedded FACTS devices. IEEE Proceedings-Generation, Transmission and Distribution", Vol.143, No.5, 1996, pp.447-454.

[14] A.K. Sahoo, S.S. Dash and T. Thyagaraja, "Power flow study including FACTS devices", Journal of applied sciences, Vol.10, 2010, pp. 15631571.

[15] C.R. "Fuerte-Esquivel, E. Acha and H. Ambriz-Perez, A thyristor controlled series compensator model for the power flow solution of practical power networks", IEEE transactions on power systems, Vol.15, No.1, 2000, pp.58-64.

[16] L. Gyugyi, "Dynamic compensation of AC transmission lines by solidstate synchronous voltage sources", IEEE Transactions on Power Delivery, Vol.9, No.2, 1994, pp. 904-911.

\section{BIOGRAPHIES}

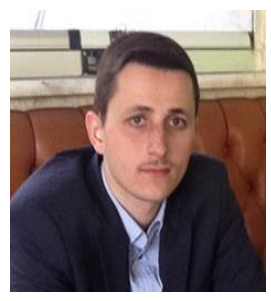

Hüseyin BAKIR was born in Sakarya, Turkey in 1991. He received the Bachelor of Science and Master on Science degrees on Electrical and Electronics Engineering in 2015 and 2017 respectively, both from the Düzce University. Presently he is a Ph.D. student at Düzce University, Department of Electrical and Electronics Engineering. His research interests include power systems and renewable energy systems. 




Ali ÖZTÜRK received his B.S. in Electrical Engineering Yildiz Technical University, Turkey, in 1996, his M.Sc. in Electrical Engineering from Sakarya University, Sakarya, Turkey, in 2001 and his Ph.D. in 2007 from the same university. His research interests include voltage stability and optimization in electric power systems.

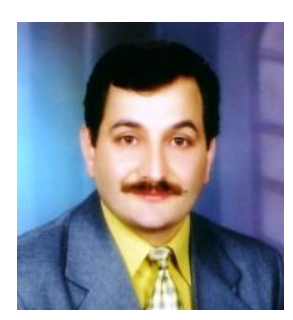

Salih TOSUN received his B.S. in Electrical Education Marmara University, Turkey, in 1986, his M.Sc. in Electrical Engineering from Marmara University, Istanbul, Turkey, in 1991. His research interests include voltage stability and optimization in electric power systems. 